\title{
Influence of Footedness on Dynamic Joint Stiffness during the Gait Stance Phase
}

\author{
Tiago Atalaia ${ }^{1^{*}}$, João M. C. S. Abrantes ${ }^{2}$ and Alexandre Castro-Caldas ${ }^{3}$ \\ ${ }^{1}$ Portuguese Red Cross Health School, Avenida de Ceuta, Edifício Urbiceuta, Piso 6, \\ 1300-125 Lisboa, Portugal. \\ ${ }^{2}$ MovLab/CICANT/Lusófona University of Humanities and Technology, Campo Grande 376, \\ 1749-024 Lisboa, Portugal. \\ ${ }^{3}$ Health Sciences Institute, Catholic University of Portugal, Travessa da Palma, 1649-023 Lisboa,
}

Portugal.

\section{Authors' contributions}

This work was carried out in collaboration between all authors. Author TA designed the study, performed the literatures searches and statistical analysis, wrote the protocol, and wrote the first draft

of the manuscript. Author JMCSA designed the study and managed the analyses of the study. Author ACC managed the analysis of the study. All authors read and approved the final manuscript.

Article Information

DOI: $10.9734 / J S R R / 2015 / 14745$

Editor(s):

(1) Vito Di Maio, Institute of Cybernetics "E. Caianiello" CNR, C / O Complex Olivetti, Via Campi Flegrei, 34, Italy.

Reviewers:

(1) Anonymous, Japan Institute of Sports Science, Japan.

(2) Anonymous, University of Haifa, Israel.

(3) Nishikant Kumar, Department of Orthopaedics, Darbhanga medical College and Hospital, Laheriasarai, Bihar, India. Complete Peer review History: http://www.sciencedomain.org/review-history.php?iid=748\&id=22\&aid=7201

\section{ABSTRACT}

Aims: Dynamic joint stiffness (DJS) is used as a joint stability indicator. The objective of the present study is to verify the influence of footedness in ankle joint stability during the gait stance phase.

Study Design: Comparative study.

Place and Duration of Study: MovLab/ CICANT/ Universidade Lusófona de Humanidades e Tecnologias, between November 2013 and June 2014

Methodology: 31 subjects (20 female and 11 male) presenting different footedness (right and left) were assessed. Ten gait stance phase trials (five each side) were recorded using a 3D motion capture system and a force platform. Synchronized ankle sagittal moment of force and angular position were used to calculate DJS for three defined sub-phases of gait stance phase: controlled 
plantar flexion, controlled dorsiflexion and powered plantar flexion. Mann-Whitney $U$ test was calculated to assess footedness influence on biomechanical variables.

Results: No significant differences were found between dominant and non-dominant limb in different combinations of footedness and gender.

Conclusion: Footedness do not seem to influence DJS and consequent joint stability. Observing the trials per participant, differences can be noted but commonly used statistical approach cannot highlight those differences. Further studies should address ankle frontal plane behaviour or assess differences at the knee and hip joints, as they could present more differences that could be statistically significant.

Keywords: Gait; dynamic joint stiffness; joint stability; footedness.

\section{INTRODUCTION}

Joint stability can be defined as control of the alignment of the joint segments and its angular position along an intended pathway, within the normal limits of the joint's movement freedom [1-3]. This ability is the sum of the contributions that passive and active joint components make to stability in typical daily living tasks. Dynamic joint stiffness (DJS) is the method usually used to study joint stability, as it serves as a joint stability indicator $[1,3]$. DJS is defined as the resistance offered by muscles and other joint structures to displacement of joint segments, and as a reaction to the external moment of force [1]. The behaviour of joint moments and angles relations [4-6] can be used to assess DJS. Kinetickinematic analysis of DJS allows observations of the spring-like behaviour of the joint and the mechanical energy exchanges $[4,6]$. In the gait stance phase the typical changes in these variables at the ankle joint sagittal plane follow a simple loop-shape plot as illustrated in Fig. 1 $[1,4,5]$. Crenna and Frigo [4] divided this loop into three basic sub-phases: the first sub-phase starts at initial contact, with a plantar flexion movement associated with a plantar flexion moment; the second sub-phase begins at load response phase, when a change in the direction of ankle movement towards dorsiflexion paired with a dorsiflexion moment can be observed; the third sub-phase start when both angle and moment decrease, indicating a plantar flexion movement and moment that occurs in preparation for the gait swing phase. Safaeepour and colleagues [6] proposed that these sub-phases could be used to calculate DJS throughout gait stance phase, naming them the controlled plantar flexion (CPF), controlled dorsiflexion (CDF) and powered plantar flexion (PPF) phases respectively.

DJS scores are calculated by computing the slope value of the linear regression line for each of the sub-phases described [6]. Examples of computed regression lines for each sub-phase, in which slope values indicate DJS, are given in Fig. 1.

The DJS score can be used to analyse joint stability; higher DJS scores indicate a stiffer, more stable joint. Several studies have shown that DJS is very consistent across ages [4], others have reported gender differences, with female subjects having lower stiffness scores then male subjects $[1,7]$. DJS seems to be influenced by gait speed, as studies have shown that it increases with speed [6].

In our review of the literature we found no studies of the relationship between DJS and footedness. Given that footedness is a demonstrable preference for using one foot rather than the other and has an impact on the functional asymmetry of movement [8-13], differences between DJS in the dominant and non-dominant lower limbs should be expected [14]. The lack of evidence on this relationship may be due to the lack of importance attached to footedness by the research study, even though some studies have suggested that footedness is a better predictor of cerebral dominance than handedness, because it is less subject to cultural influences $[13,15]$.

Both self-report questionnaires and observation of performance are routinely used to assess footedness and there is no consensus on which measure is best in spite of a considerable body of evidence [12,15-17]. We used the Lateral Preference Inventory as it has good reliability in the assessment of lateral profile, which comprises handedness, footedness, eyedness and earedness [16].

Gait asymmetries can be consequences of asymmetries in the contribution of left and right limbs to the gait propulsion and control 

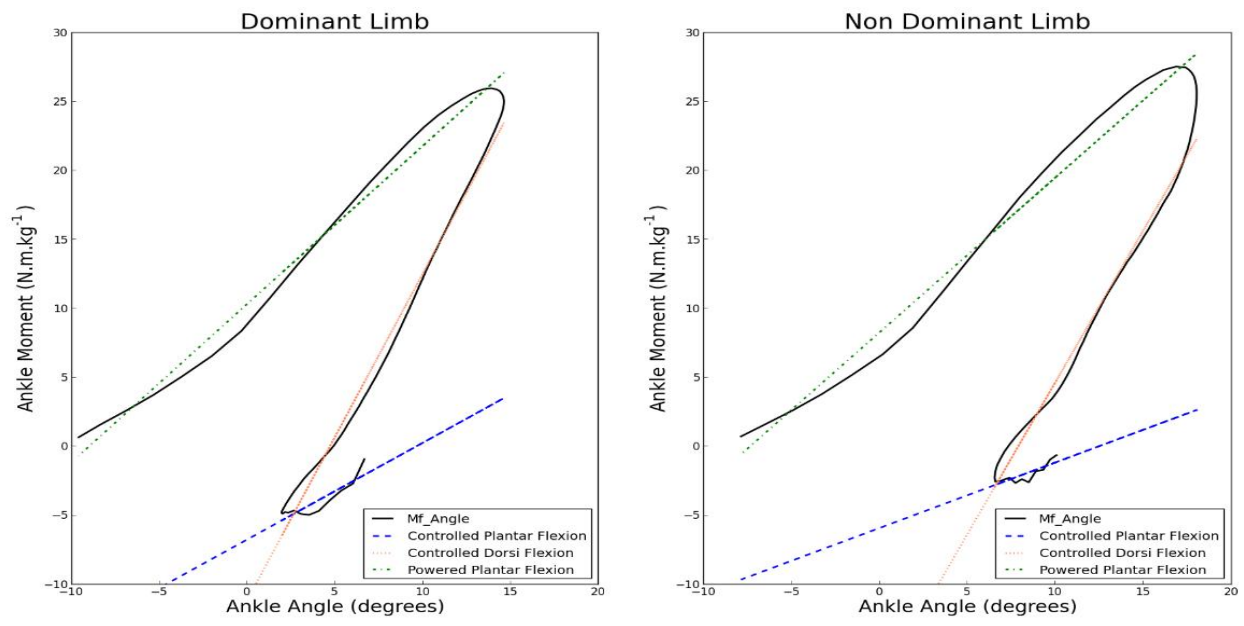

Fig. 1. Example of ankle joint moment-angle plot for the dominant and non-dominant lower limb, selected from the study sample.

phases [18]. So the aim of this study was to investigate the influence of footedness on ankle sagittal plane DJS during the gait stance phase. It was hypothesised that inter-limb differences should be present in the right-footed and leftfooted groups. This analysis could be used to make a more objective assessment of footedness, as it relies on use of biomechanical indicators, which would have benefits in injury prevention and rehabilitation settings.

\section{METHODOLOGY}

\subsection{Subjects and Procedures}

Subjects were selected by online invitation. Invitations included a description of the purpose of the study and procedures used and subjects provided informed consent in accordance with Helsinki Declaration. Subjects were sent an online version of the Lateral Performance Inventory (LPI) [16] to complete, online questionnaires have proved to be reliable [19], so we chose to use an online version to allow us to increase the sample size. A total of 164 subjects completed the LPI and a sample of 31 of these was selected for laboratory-based performance assessments on the basis of the following criteria: age between 18 and 40 years, with no history of ankle injury or instability, assessed prior to the data collection procedures. We deliberately selected a sample containing as many left-footed subjects as possible. The sample was made up of 20 females (mean age $=$ 23.0 years \pm 2.98 ; mean weight $=60.3 \pm 9.8 \mathrm{~kg}$; mean height $=163 \pm 6.3 \mathrm{~cm}$ ) and 11 males (mean age 23.64 years \pm 2.25 ; mean weight $=$
$74.4 \pm 11.6 \mathrm{~kg} ;$ mean height $=176.1 \pm 5.1$ ). Footedness distribution was $85 \%$ right-footed and $15 \%$ left-footed in the female subjects and $72.73 \%$ right-footed and $27.27 \%$ left-footed in the male subjects. Footedness scores were calculated in accordance with LPI instructions [16].

The experimental procedure involved the readministration of the LPI prior to the collection of other data; rather than providing verbal responses subjects were asked to perform each task whilst the examiner observed their behaviour. This allowed us to confirm footedness and the other indices of laterality included in the LPI. Biomechanical data were collected at MovLab (Universidade Lusófona de Humanidades e Tecnologias, Lisbon, Portugal). Gait kinematic data were recorded at $200 \mathrm{~Hz}$ using a 3D motion capture system (Vicon®Motion Capture MX System, Oxford UK), composed of $9 \mathrm{MX}\left(7^{*} 1.3 \mathrm{~Gb} ; 2^{*} 2.0 \mathrm{~Gb}\right)$ which were connected to the MXUltranet control hardware and used to track the motion of the 41 spherical reflexive markers $(9.5 \mathrm{~mm}$ diameter) that make up the PluglnGait-Full Body model. Anthropometric data, needed for the PluglnGaitFull Body model, were collected using the SECA 764 scale and Siber Hegner anthropometric measurement instruments. Synchronized kinetic data were recorded at $1000 \mathrm{~Hz}$ using a force platform (AMTI BP400600-2000, USA) connected to a strain gauge amplifier (AMTI MSA-6 MiniAmp). The subjects were instructed to walk barefoot along a $7 \mathrm{~m}$ path at their normal speed. The path was in the form of a loop so that subjects could complete one walk trial at a stable 
speed, without stopping. Subjects were instructed to maintain a constant walking speed and avoid targeting the force platform. A total of 10 sets of gait stance phase data per subject were selected for analysis (5 each side) from the valid sets (those in which all the stance subphases were present)

\subsection{Data Processing}

Kinematic and kinetic data acquisition and processing was done using Vicon ${ }^{\circledR}$ Nexus software (version 1.7.1), with a Woltring filter routine [20,21]. Ankle moment of force (normalized to body weight) and joint angle were normalized to percentages of the gait stance phase to allow inter-limb comparisons. The moment-angle plot for each stance phase in all participants was calculated using the method described by Safaeepour and colleagues [6]: the loop is divided into three sub-phases, CPF, CDF and PPF, as described above. Ankle joint DJS in each sub-phase was calculated using the standard formula $D J S=d M / d \theta$, where $M$ is the ankle moment of force and $\theta$ is the ankle sagittal angle $[1,4,6]$. Least-squares regression models were used to calculate regression lines for each of the sub-phases6. The DJS calculation was performed for every trial of every participant. Mean DJS values for each participant were used in the statistical analysis. The KolmogorovSmirnov test showed that scores were not normally distributed so the Mann-Whitney $U$ test was used to assess the influence of footedness on DJS scores. Statistical analysis was carried out using the Statistical Package for Social Sciences software (SPSS version 20, IBM, USA).

\section{RESULTS AND DISCUSSION}

Table 1 shows the regression fit given by the coefficient of determination (R2) for each of the regression lines used for DJS calculation. The data are grouped according to gait stance subphase and dominant foot. On the dominant side mean values of DJS in each sub-phase were CPF: $0.46 \pm 0.27$ range 0.07 to 1.22 ; CDF: $1,43 \pm 0.44$, range 0.82 to 2.56 ; PPF: $1.01 \pm 0.27$ range 0.59 to 1.77 . On the non-dominant side mean DJS values were CPF: $0.50 \pm 0.32$, range 0 to 1.72 ; CDF: $1.43 \pm 0.40$ range 0.82 to 2,34 ; PPF: $1.06 \pm 0.26$, range from 0.56 to 1.48 . On the dominant side mean values of $\mathrm{R} 2$ in each subphase were CPF: $0.73 \pm 0.24$, range 0.03 to 0.95 ; CDF: $0.91 \pm 0.06$ range 0.79 to 0.98 ; PPF: $0.97 \pm 0.04$ range 0.80 to 1.00 . On the nondominant side mean $\mathrm{R} 2$ values were CPF:
$0.73 \pm 0.22$, range 0.07 to 0.97 ; CDF: $0.91 \pm 0.07$ range 0.64 to 0.98 ; PPF: $0.97 \pm 0.04$, range from 0.84 to 1.00 .

Separate analyses of all three sub-phases were carried out for the dominant and non-dominant feet and for each gender, as there are reported to be gender differences in DJS [7]. Results of the Kolmogorov-Smirnov test indicated that the data were not normally distributed so we used the Mann-Whitney $U$ test to assess the influence of footedness on DJS. Data were grouped according to footedness and gender: female and male right-footed groups and female and male left-footed groups. The results of the MannWhitney $U$ tests are presented in Tables 2 and 3.

The Mann Whitney $U$ test indicated that in male and female right-footed subjects DJS was similar on the dominant and non-dominant sides, and in all the sub-phases, suggesting that there was no influence of footedness on joint stability at any point in the gait stance phase.

Table 3 shows that similar results were found for the left-footed group.

Gait is often assumed to be symmetrical in the lower limbs in order to facilitate gait analysis. Asymmetry is considered pathological [18], but some asymmetry may be the expression of a natural functional difference between the lower limbs [18], possibly related to footedness. This led us to assess lower limb dominance differences in joint stability, operationalised as DJS, during the gait stance phase. DJS values in the CPF were lower than in the other subphases, with the regression lines also showing a lower value for R2. Other studies have reported similar differences between the sub-phases and attributed them to the brevity of the CPF subphase and the sampling rate used $(100 \mathrm{~Hz})$ [6]. In our study, we used a higher sampling rate $(200 \mathrm{~Hz})$ which may explain why we obtained higher DJS scores in the CPF sub-phase than. safaeepour and colleagues (for gait at normal speed) although they were still lower than in the other sub-phases and were associated with lower R2 scores [6]. We found similar DJS and $\mathrm{R} 2$ values in the CDF and PPF sub-phases to those reported in other studies $[4,6]$. Our data provide no evidence to suggest that footedness influences lower limb DJS and no evidence for gender- or dominance-related differences in DJS. 
Atalaia et al.; JSRR, 5(2): 175-183, 2015; Article no.JSRR. 2015.085

Table 1. Individual and sample mean scores for DJS and coefficient of regression (R2) grouped according to gait sub-phase

\begin{tabular}{|c|c|c|c|c|c|c|c|c|c|c|c|c|c|c|c|c|c|c|}
\hline & \multicolumn{6}{|c|}{ CPF } & \multicolumn{6}{|c|}{ CDF } & \multicolumn{6}{|c|}{ PPF } \\
\hline & Domir & & & Non-D & inant & & Domin & & & Non-D & inant & & Domin & & & Non-D & inant & \\
\hline $\begin{array}{l}\text { Partici- } \\
\text { pants }\end{array}$ & $\begin{array}{l}\text { Mean } \\
\text { DJS }\end{array}$ & $\begin{array}{l}\text { Mean } \\
R^{2}\end{array}$ & $\begin{array}{l}\text { St } \\
\text { Dev }\end{array}$ & $\begin{array}{l}\text { Mean } \\
\text { DJS }\end{array}$ & $\begin{array}{l}\text { Mean } \\
R^{2}\end{array}$ & $\begin{array}{l}\text { St } \\
\text { Dev }\end{array}$ & $\begin{array}{l}\text { Mean } \\
\text { DJS }\end{array}$ & $\begin{array}{l}\text { Mean } \\
R^{2}\end{array}$ & $\begin{array}{l}\text { St } \\
\text { Dev }\end{array}$ & $\begin{array}{l}\text { Mean } \\
\text { DJS }\end{array}$ & $\begin{array}{l}\text { Mean } \\
R^{2}\end{array}$ & $\begin{array}{l}\text { St } \\
\text { Dev }\end{array}$ & $\begin{array}{l}\text { Mean } \\
\text { DJS }\end{array}$ & $\begin{array}{l}\text { Mean } \\
R^{2}\end{array}$ & $\begin{array}{l}S t \\
\text { Dev }\end{array}$ & $\begin{array}{l}\text { Mean } \\
\text { DJS }\end{array}$ & $\begin{array}{l}\text { Mean } \\
R^{2}\end{array}$ & $\begin{array}{l}\text { St } \\
\text { Dev }\end{array}$ \\
\hline P01 & 0,85 & 0,92 & 0,00 & 0,61 & 0,93 & 0,08 & 1,95 & 0,96 & 0,05 & 1,88 & 0,92 & 0,06 & 1,19 & 0,99 & 0,03 & 1,15 & 0,99 & 0,02 \\
\hline P02 & 0,41 & 0,76 & 0,00 & 0,74 & 0,80 & 0,12 & 1,93 & 0,98 & 0,04 & 2,32 & 0,97 & 0,05 & 1,11 & 0,97 & 0,03 & 1,20 & 0,99 & 0,02 \\
\hline P03 & 0,17 & 0,52 & 0,02 & 0,18 & 0,56 & 0,06 & 1,24 & 0,97 & 0,03 & 0,99 & 0,95 & 0,02 & 0,69 & 0,97 & 0,02 & 0,83 & 0,99 & 0,02 \\
\hline P04 & 0,42 & 0,90 & 0,00 & 0,34 & 0,62 & 0,11 & 1,75 & 0,81 & 0,10 & 1,54 & 0,77 & 0,10 & 1,12 & 0,98 & 0,04 & 1,48 & 0,88 & 0,06 \\
\hline P05 & 0,27 & 0,57 & 0,04 & 0,38 & 0,77 & 0,08 & 1,34 & 0,90 & 0,07 & 1,21 & 0,94 & 0,04 & 0,73 & 1,00 & 0,01 & 0,71 & 0,91 & 0,03 \\
\hline P06 & 0,37 & 0,75 & 0,01 & 0,45 & 0,76 & 0,10 & 1,01 & 0,93 & 0,03 & 1,03 & 0,91 & 0,04 & 0,70 & 0,97 & 0,03 & 0,85 & 0,99 & 0,01 \\
\hline P07 & 0,44 & 0,90 & 0,00 & 0,70 & 0,89 & 0,11 & 0,93 & 0,93 & 0,03 & 1,62 & 0,92 & 0,05 & 0,73 & 0,99 & 0,02 & 1,29 & 0,99 & 0,04 \\
\hline P08 & 0,55 & 0,87 & 0,00 & 0,32 & 0,64 & 0,08 & 1,33 & 0,91 & 0,05 & 1,96 & 0,87 & 0,09 & 0,99 & 0,99 & 0,03 & 1,03 & 0,98 & 0,03 \\
\hline P09 & 0,65 & 0,80 & 0,02 & 0,45 & 0,92 & 0,04 & 1,61 & 0,97 & 0,03 & 1,96 & 0,89 & 0,08 & 1,01 & 0,98 & 0,03 & 1,33 & 0,99 & 0,02 \\
\hline P10 & 1,22 & 0,93 & 0,00 & 1,72 & 0,89 & 0,26 & 2,56 & 0,94 & 0,08 & 2,34 & 0,96 & 0,06 & 1,26 & 0,97 & 0,04 & 1,23 & 0,99 & 0,02 \\
\hline P11 & 0,31 & 0,82 & 0,00 & 0,40 & 0,81 & 0,07 & 0,94 & 0,92 & 0,03 & 1,31 & 0,92 & 0,05 & 1,07 & 0,97 & 0,05 & 1,01 & 0,98 & 0,03 \\
\hline P12 & 0,32 & 0,66 & 0,01 & 0,22 & 0,44 & 0,08 & 2,07 & 0,88 & 0,10 & 1,61 & 0,88 & 0,07 & 1,20 & 0,99 & 0,02 & 1,37 & 0,99 & 0,02 \\
\hline P13 & 0,16 & 0,48 & 0,09 & 0,33 & 0,83 & 0,06 & 1,23 & 0,94 & 0,03 & 1,19 & 0,96 & 0,03 & 1,21 & 1,00 & 0,02 & 1,04 & 0,99 & 0,02 \\
\hline P14 & 0,26 & 0,86 & 0,00 & 0,00 & 0,18 & 0,08 & 1,16 & 0,97 & 0,02 & 1,04 & 0,97 & 0,02 & 0,77 & 0,97 & 0,03 & 0,86 & 0,98 & 0,03 \\
\hline P15 & 0,11 & 0,25 & 0,26 & 0,11 & 0,28 & 0,07 & 1,54 & 0,95 & 0,04 & 0,86 & 0,92 & 0,03 & 0,87 & 0,94 & 0,05 & 0,96 & 0,98 & 0,04 \\
\hline P16 & 0,25 & 0,25 & 0,42 & 0,67 & 0,73 & 0,18 & 1,21 & 0,89 & 0,05 & 1,50 & 0,87 & 0,07 & 1,44 & 0,99 & 0,03 & 1,43 & 0,99 & 0,04 \\
\hline P17 & 0,75 & 0,92 & 0,05 & 0,38 & 0,89 & 0,04 & 0,97 & 0,96 & 0,02 & 0,92 & 0,98 & 0,02 & 0,59 & 0,99 & 0,01 & 0,56 & 0,98 & 0,01 \\
\hline P18 & 1,07 & 0,91 & 0,00 & 0,76 & 0,76 & 0,14 & 2,36 & 0,96 & 0,06 & 1,91 & 0,97 & 0,04 & 1,11 & 1,00 & 0,02 & 1,19 & 0,98 & 0,03 \\
\hline P19 & 0,57 & 0,92 & 0,00 & 0,74 & 0,97 & 0,06 & 1,64 & 0,91 & 0,06 & 1,48 & 0,93 & 0,05 & 1,14 & 0,97 & 0,04 & 1,18 & 0,98 & 0,04 \\
\hline P20 & 0,62 & 0,93 & 0,00 & 0,60 & 0,86 & 0,12 & 1,09 & 0,92 & 0,04 & 1,02 & 0,85 & 0,05 & 0,83 & 0,97 & 0,03 & 1,06 & 0,94 & 0,04 \\
\hline P21 & 0,67 & 0,89 & 0,00 & 0,45 & 0,79 & 0,09 & 1,06 & 0,94 & 0,03 & 1,29 & 0,92 & 0,05 & 1,23 & 0,80 & 0,02 & 1,07 & 0,99 & 0,02 \\
\hline P22 & 0,42 & 0,70 & 0,02 & 0,59 & 0,86 & 0,10 & 1,01 & 0,83 & 0,06 & 1,06 & 0,84 & 0,06 & 0,81 & 0,99 & 0,02 & 0,84 & 0,99 & 0,02 \\
\hline P23 & 0,50 & 0,88 & 0,00 & 0,29 & 0,83 & 0,05 & 1,49 & 0,96 & 0,04 & 1,40 & 0,96 & 0,04 & 1,34 & 0,99 & 0,04 & 1,48 & 0,99 & 0,03 \\
\hline P24 & 0,44 & 0,57 & 0,12 & 0,55 & 0,57 & 0,20 & 1,36 & 0,81 & 0,08 & 1,33 & 0,64 & 0,13 & 1,04 & 0,99 & 0,02 & 1,05 & 0,88 & 0,04 \\
\hline P25 & 0,07 & 0,39 & 0,34 & 0,23 & 0,60 & 0,06 & 1,56 & 0,83 & 0,09 & 1,48 & 0,93 & 0,05 & 1,06 & 0,99 & 0,02 & 1,15 & 1,00 & 0,02 \\
\hline P26 & 0,46 & 0,74 & 0,06 & 0,78 & 0,88 & 0,16 & 1,28 & 0,96 & 0,04 & 1,31 & 0,97 & 0,03 & 0,59 & 0,83 & 0,03 & 0,57 & 0,84 & 0,03 \\
\hline P27 & 0,24 & 0,95 & 0,00 & 0,59 & 0,97 & 0,06 & 0,82 & 0,85 & 0,04 & 0,82 & 0,93 & 0,03 & 0,73 & 0,98 & 0,03 & 0,73 & 1,00 & 0,01 \\
\hline P28 & 0,60 & 0,93 & 0,01 & 0,46 & 0,84 & 0,11 & 1,46 & 0,83 & 0,08 & 1,60 & 0,87 & 0,08 & 1,24 & 0,98 & 0,04 & 1,21 & 0,99 & 0,03 \\
\hline P29 & 0,36 & 0,81 & 0,00 & 0,95 & 0,92 & 0,12 & 1,07 & 0,95 & 0,03 & 1,59 & 0,97 & 0,04 & 0,85 & 0,99 & 0,02 & 0,80 & 0,96 & 0,02 \\
\hline P30 & 0,08 & 0,03 & 0,80 & 0,19 & 0,07 & 0,40 & 2,10 & 0,79 & 0,13 & 1,73 & 0,84 & 0,10 & 1,77 & 0,99 & 0,05 & 1,46 & 0,92 & 0,05 \\
\hline P31 & 0,59 & 0,73 & 0,08 & 0,49 & 0,74 & 0,15 & 1,35 & 0,95 & 0,04 & 1,10 & 0,93 & 0,04 & 0,90 & 0,97 & 0,03 & 0,90 & 0,94 & 0,03 \\
\hline Mean & 0,46 & 0,73 & & 0,50 & 0,73 & & 1,43 & 0,91 & & 1,43 & 0,91 & & 1,01 & 0,97 & & 1,06 & 0,97 & \\
\hline StDev & 0,27 & 0,24 & & 0,32 & 0,22 & & 0,44 & 0,06 & & 0,40 & 0,07 & & 0,27 & 0,04 & & 0,26 & 0,04 & \\
\hline
\end{tabular}


Table 2. Mann-Whitney U test for the right-footed group. Analysis by gender

\begin{tabular}{|c|c|c|c|c|c|c|c|}
\hline \multicolumn{8}{|c|}{ Ranks } \\
\hline & \multicolumn{4}{|c|}{ Right-Footed Female } & \multicolumn{3}{|c|}{ Right-Footed Male } \\
\hline & Dominance & $\mathbf{N}$ & Mean rank & Sum of ranks & $\mathbf{N}$ & Mean rank & Sum of ranks \\
\hline \multirow[t]{3}{*}{ CPF } & Dominant & 17 & 17,71 & 301,00 & 8 & 6,25 & 50,00 \\
\hline & Non-dominant & 17 & 17,29 & 294,00 & 8 & 10,75 & 86,00 \\
\hline & Total & 34 & & & 16 & & \\
\hline \multirow[t]{3}{*}{ CDF } & Dominant & 17 & 18,06 & 307,00 & 8 & 7,38 & 59,00 \\
\hline & Non-dominant & 17 & 16,94 & 288,00 & 8 & 9,63 & 77,00 \\
\hline & Total & 34 & & & 16 & & \\
\hline \multirow[t]{3}{*}{ PPF } & Dominant & 17 & 15,71 & 267,00 & 8 & 7,88 & 63,00 \\
\hline & Non-dominant & 17 & 19,29 & 328,00 & 8 & 9,13 & 73,00 \\
\hline & Total & 34 & & & 16 & & \\
\hline \multicolumn{8}{|c|}{ Test statistics } \\
\hline & & \multicolumn{3}{|c|}{ Female } & \multicolumn{3}{|c|}{ Male } \\
\hline & & CPF & CDF & PPF & CPF & CDF & PPF \\
\hline \multicolumn{2}{|c|}{ Mann-Whitney U } & 141,000 & 135,000 & 114,000 & 14,000 & 23,000 & 27,000 \\
\hline \multicolumn{2}{|c|}{ Wilcoxon W } & 294,000 & 288,000 & 267,000 & 50,000 & 59,000 & 63,000 \\
\hline \multicolumn{2}{|c|}{$\mathrm{Z}$} & $-0,121$ & $-0,327$ & $-1,051$ & $-1,890$ & $-0,945$ & $-0,525$ \\
\hline \multicolumn{2}{|c|}{ Asymp. Sig. (2-taliled) } & 0,904 & 0,744 & 0,293 & 0,059 & 0,345 & 0,600 \\
\hline \multicolumn{2}{|c|}{ Exact Sig. [2*(1-Tailed Sig.)] } & $0,919^{a}$ & $0,760^{a}$ & $0,306^{a}$ & $0,065^{a}$ & $0,382^{a}$ & $0,645^{a}$ \\
\hline
\end{tabular}

a. Not corrected for ties 
Table 3. Mann-Whitney U test for the left-footed group. Analysis by gender

\begin{tabular}{|c|c|c|c|c|c|c|c|}
\hline \multicolumn{8}{|c|}{ Ranks } \\
\hline & \multicolumn{4}{|c|}{ Left-Footed Female } & \multicolumn{3}{|c|}{ Left-Footed Male } \\
\hline & Dominance & $\mathbf{N}$ & Mean rank & Sum of ranks & $\mathbf{N}$ & Mean rank & Sum of ranks \\
\hline \multirow[t]{3}{*}{ CPF } & Dominant & 3 & 4,33 & 13,00 & 3 & 3,00 & 9,00 \\
\hline & Non-dominant & 3 & 2,67 & 8,00 & 3 & 4,00 & 12,00 \\
\hline & Total & 6 & & & 6 & & \\
\hline \multirow[t]{3}{*}{ CDF } & Dominant & 3 & 3,67 & 11,00 & 3 & 4,33 & 13,00 \\
\hline & Non-dominant & 3 & 3,33 & 10,00 & 3 & 2,67 & 8,00 \\
\hline & Total & 6 & & & 6 & & \\
\hline \multirow[t]{3}{*}{ PPF } & Dominant & 3 & 4,00 & 12,00 & 3 & 3,67 & 11,00 \\
\hline & Non-dominant & 3 & 3,00 & 9,00 & 3 & 3,33 & 10,00 \\
\hline & Total & 6 & & & 6 & & \\
\hline \multicolumn{8}{|c|}{ Test statistics } \\
\hline & & \multicolumn{3}{|c|}{ Female } & \multicolumn{3}{|l|}{ Male } \\
\hline & & CPF & CDF & PPF & CPF & CDF & PPF \\
\hline \multicolumn{2}{|c|}{ Mann-Whitney U } & 2,000 & 4,000 & 3,000 & 3,000 & 2,000 & 4,000 \\
\hline \multicolumn{2}{|c|}{ Wilcoxon W } & 8,000 & 10,000 & 9,000 & 9,000 & 8,000 & 10,000 \\
\hline \multicolumn{2}{|l|}{ Z } & $-1,091$ & $-0,218$ & $-0,655$ & $-0,655$ & $-1,091$ & $-0,218$ \\
\hline \multicolumn{2}{|c|}{ Asymp. Sig. (2-taliled) } & 0,275 & 0,827 & 0,513 & 0,513 & 0,275 & 0,827 \\
\hline \multicolumn{2}{|c|}{ Exact Sig. [2*(1-Tailed Sig. $)]$} & $0,400^{a}$ & $1,000^{a}$ & $0,700^{a}$ & $0,700^{a}$ & $0,400^{a}$ & $1,000^{a}$ \\
\hline
\end{tabular}


Joint stability during the gait stance phase seems to be similar in the dominant and non-dominant limbs, DJS scores were similar in left and right lower limbs. We predicted that there would be dominance-related gait asymmetries reflecting the normal functional asymmetries present in any human movement [18]. The moment-angle plots of individual subjects, such as that shown Fig. 1 show small differences between sides but no consistent difference was detectable at group level using statistical tests. Some authors have speculated about the existence of inter-limb differences, including differences related to footedness, but it is difficult to find evidence of such differences using common movement timedependent descriptive data $[4,6,14,18]$. In this study we used kinematic-kinetic analysis to investigate potential inter-limb differences in joint stability; we expected to detect effects of footedness on dynamic ankle sagittal plane behaviour during the gait stance phase, as suggested by other studies $[1,4,6]$. Even using this approach we failed to find evidence for the influence of footedness on lower limb stability in the gait stance phase. These findings are relevant to injury prevention and rehabilitation as it is assumed that there are muscle imbalances between dominant and non-dominant lower limbs $[22,23]$, perhaps large enough to render use of the contralateral limb for strength comparison questionable [24]. Taken together our data and previous data suggest that gait alone is not suitable as a substrate for assessing the influence of footedness on human movement, as its time course and energetic demands do lend themselves to the demonstration of inter-limb differences.

\section{CONCLUSION}

Footedness does not appear to influence ankle joint sagittal DJS scores during the gait stance phase. This indicates that joint stability is similar in the dominant and non-dominant limbs. Sagittal ankle joint stability during gait stance cannot be used as an indicator of footedness. The assessment of footedness and laterality differences will require the use of other dynamic analysis tools as any laterality differences appear to be small and are not detected using common statistical tests. Further studies could assess ankle frontal plane behaviour or dominance differences in joint stability at the knee and hip joints, as dominance effects may be detectable in more proximal joint behavior.

\section{CONSENT}

All authors declare that written informed consent was obtained from the patient (or other approved parties) for publication of this case report and accompanying images.

\section{ETHICAL APPROVAL}

All authors hereby declare that all procedures have been performed in accordance with the ethical standards laid down in the 1964 Declaration of Helsinki. The present study was approved by the ethical board of the Escola Superior de Saúde da Cruz Vermelha Portuguesa.

\section{ACKNOWLEDGEMENTS}

The authors wish to thanks to all members of the MovLab team (http://movlab.ulusofona.pt/ for their assistance, in particular Ivo Roupa for precious help in the data computation and José Maria Dinis for help with data collection procedures.

\section{COMPETING INTERESTS}

Authors have declared that no competing interests exist.

\section{REFERENCES}

1. Gabriel RC, Abrantes J, Granata K, BulasCruz J, Melo-Pinto P, Filipe V. Dynamic joint stiffness of the ankle during walking: gender-related differences. Phys Ther Sport. 2008;9(1):16-24.

2. Atalaia T, Abrantes JMCS. Medial-lateral CoP-Rearfoot relation during stance. In: Jorge RN, Tavares JMRS, Pinotti M, Slade A, editors. Proceedings of the 6th International Conference on Technology and Medical Sciences Porto: Taylor \& Francis Group - CRC Press. 2011;177-81.

3. Abrantes J. Rigidez Dinâmica como Indicador da Estabilidade Articular. São Pedro, São Paulo - Brasil: XII Congresso Brasileiro de Biomecânica; 2007.

4. Crenna P, Frigo C. Dynamics of the ankle joint analyzed through moment-angle loops during human walking: gender and age effects. Hum Mov Sci. 2011;30(6):1185-98.

5. Frigo C, Crenna P, Jensen LM. Momentangle relationship at lower limb joints during human walking at different velocities. J Electromyogr Kinesiol. 1996;6(3):177-90. 
6. Safaeepour Z, Esteki A, Ghomshe FT, Abu Osman NA. Quantitative analysis of human ankle characteristics at different gait phases and speeds for utilizing in anklefoot prosthetic design. Biomed Eng Online. 2014;13(1):19.

7. Granata KP, Padua DA, Wilson SE. Gender differences in active musculoskeletal stiffness. Part II. Quantification of leg stiffness during functional hopping tasks. J Electromyogr Kinesiol. 2002;12(2): 127-35.

8. Grouios G, Hatzitaki V, Kollias N, Koidou I. Investigating the stabilising and mobilising features of footedness. Laterality. 2009; 14(4):362-80.

9. Hart S, Gabbard C. Examining the mobilizing feature of footedness. Percept Mot Skills. 1998;86(3 Pt 2):1339-42.

10. Iteya M, Gabbard C, Hart S. Limb laterality and motor proficiency in children. Int $\mathrm{J}$ Neurosci. 1995;83(3-4):275-9.

11. Iteya M, Gabbard C, Okada M. Lower-limb speed and foot preference in children. Percept Mot Skills. 1995;81(3):1115-8.

12. Peters M. Footedness: asymmetries in foot preference and skill and neuropsychological assessment of foot movement. Psychol Bull. 1988;103(2):179-92.

13. Wang Z, Newell KM. Footedness exploited as a function of postural task asymmetry. Laterality. 2013;18(3):303-18.

14. Ebben WP, Flanagan $E$, Jensen RL. Bilateral facilitation and laterality during the countermovement jump. Percept Mot Skills. 2009;108(1):251-8.

15. Kalaycioglu C, Kara C, Atbasoglu C, Nalcaci E. Aspects of foot preference: Differential relationships of skilled and unskilled foot movements with motor asymmetry. Laterality. 2008;13(2):124-42.

16. Coren $\mathrm{S}$. The Lateral Preference Inventory for measurement of handedness, footedness, eyedness and earedness Norms for young-adults. Bull Psychon Soc. 1993;31(1):1-3.
17. Coren S, Porac C. The validity and reliability of self-report items for the measurement of lateral preference. $\mathrm{Br} \mathrm{J}$ Psychol. 1978;69(2):207.

18. Sadeghi $H$, Allard $P$, Prince $F$, Labelle $H$. Symmetry and limb dominance in ablebodied gait: a review. Gait Posture. 2000;12(1):34-45.

19. Turner MR, Wicks $P$, Brownstein CA, Massagli MP, Toronjo M, Talbot K, et al. Concordance between site of onset and limb dominance in amyotrophic lateral sclerosis. J Neurol Neurosurg Psychiatry. 2010(82):853-4.

20. Woltring HJ. A Fortran package for generalized, cross-validatory spline smoothing and differentiation. Adv Eng Software. 1986;8(2):104-13.

21. Woltring HJ. GCVSPL software package Release Notes: International Society of Biomechanics; 1986.

Available:http://isbweb.org/software/sigpro c/gcvspl/gcvspl.memo.

22. Hageman PA, Gillaspie DM, Hill LD. Effects of speed and limb dominance on eccentric and concentric isokinetic testing of the knee. J Orthop Sports Phys Ther. 1988;10(2):59-65.

23. Baumeister J, Reis C, Weiss M. Influence of limb dominance on knee flexor:extensor ratio of $\mathrm{ACL}$ reconstructed patients. (Poster Session). Isokinet Exerc Sci. 2004;12(1):59-61.

24. Kovaleski JE, Heitman RJ, Gurchiek LR, Erdmann JW, Trundle TL. Reliability and effects of leg dominance on lower extremity isokinetic force and work using the Closed Chain Rider System. / Robustesse et effets de dominance de la jambe sur la force isocinetique des extremites des membres inferieurs en faisant un travail musculaire a l'aide d'un ergometre a chaine de velo. J Sport Rehabil. 1997;6(4):319-26.

(c) 2015 Atalaia et al.; This is an Open Access article distributed under the terms of the Creative Commons Attribution License (http://creativecommons.org/licenses/by/4.0), which permits unrestricted use, distribution, and reproduction in any medium, provided the original work is properly cited.

\section{Peer-review history:}

The peer review history for this paper can be accessed here: http://www.sciencedomain.org/review-history.php?iid=748\&id=22\&aid=7201 